\title{
Antibacterial activities of almond skins on cagA-positive and-negative clinical isolates of Helicobacter pylori
}

\author{
Carlo Bisignano ${ }^{1 \dagger}$, Angela Filocamo $^{1 \dagger}$, Erminia La Camera $^{1 \dagger}$, Sebastiana Zummo ${ }^{2 \dagger}$, Maria Teresa Fera ${ }^{2 \dagger}$ \\ and Giuseppina Mandalari ${ }^{1,3^{*}+}$
}

\begin{abstract}
Background: Helicobacter pylori is known to be a gastric pathogen of humans. Eradication regimens for H. pylori infection have some side effects, compliance problems, relapses, and antibiotic resistance. Therefore, the need for alternative therapies for $\mathrm{H}$. pylori infections is of special interest. We have previously shown that polyphenols from almond skins are active against a range of food-borne pathogens. The aim of this study was to evaluate the antibacterial effects of natural almond skins before and after simulated human digestion and the pure flavonoid compounds epicatechin, naringenin and protocatechuic acid against $H$. pylori.
\end{abstract}

Results: H. pylori strains were isolated from gastric biopsy samples following standard microbiology procedures. Also, cagA and vacA genes were identified using PCR. Susceptibility studies on 34 strains of H. pylori, including two reference strains (ATCC 43504, ATCC 49503), were performed by the standard agar dilution method. Natural almond skin was the most effective compound against H. pylori (MIC range, 64 to $128 \mu \mathrm{g} / \mathrm{ml}$ ), followed by natural skin post gastric digestion (MIC range, 128 to $512 \mu \mathrm{g} / \mathrm{ml}$ ), and natural almond skin post gastric plus duodenal digestion (MIC range, 256 to $512 \mu \mathrm{g} / \mathrm{ml}$ ). Amongst the pure flavonoid compounds, protocatechuic acid showed the greatest activity (MIC range, 128 to $512 \mu \mathrm{g} / \mathrm{ml}$ ) against $\mathrm{H}$. pylori strains.

Conclusions: Polyphenols from almond skins were effective in vitro against $H$. pylori, irrespective of genotype status and could therefore be used in combination with antibiotics as a novel strategy for antibiotic resistance.

Keywords: Helicobacter pylori, Flavonoids, Almond skins, Epicathechin, Naringerin, Protocatechuic acid

\section{Background}

Helicobacter pylori is a microaerophilic Gram-negative bacterium which colonizes the human gastric mucosa. It is known to be a gastric pathogen of humans associated with chronic gastritis, peptic ulcers, atrophic gastritis, intestinal metaplasia and lymphoma or cancer development $[1,2]$. Approximately $50 \%$ of the world population is infected with $H$. pylori, with prevalence rates ranging from $20 \%$ to more than $80 \%$ in certain countries [3]. $H$. pylori has been identified as group 1 carcinogen by the

\footnotetext{
* Correspondence: gmandalari@unime.it

${ }^{\dagger}$ Equal contributors

'Dipartimento di Scienze del Farmaco e Prodotti per la Salute, University of Messina, Viale Annunziata, Messina 98100, Italy

${ }^{3}$ The Model Gut, Institute of Food Research, Norwich Research Park, Colney Lane, Norwich NR4 7UA, UK

Full list of author information is available at the end of the article
}

International Agency for Research on Cancer [4]. The observation that only a subset of infected individuals develops severe gastroduodenal diseases may depend on the virulence of the infecting organism. Amongst the different genetic determinants involved in $H$. pylori virulence are the cytotoxin-associated gene (cagA) and the vacuolating cytotoxin gene $(v a c A)$. $V a c A$, which is present in all $H$. pylori strains, contains at least two variable parts relevant to virulence [5]. The s region encoding the signal peptide exists as s1 or s2 allelic types, and the $\mathrm{m}$ region (middle) occurs as $\mathrm{m} 1$ and $\mathrm{m} 2$ allelic types [6]. CagA, which is not present in every $H$. pylori strain [7], is a marker for a pathogenicity island (PAI) [8] associated with more severe clinical outcomes [9]. It has also been demonstrated that $C a g A$ is required to disrupt the organization of apical junctions and perturb epithelial

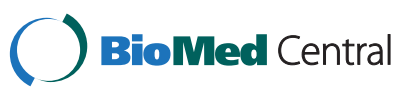


differentiation [10]. Type $\mathrm{s} 1 / \mathrm{m} 1$ strains produce a higher level of cytotoxin activity than other genotypes. A strong association between $\operatorname{cag} A$ and $v a c A$ signal sequence type $\mathrm{s} 1$ has been reported [5]. Strains carrying s1 m1 mosaic combination secrete vacuolating cytotoxin in contrast to those with $\mathrm{s} 2 \mathrm{~m} 2$ activity [11].

The standard treatment for $H$. pylori related disease is a combination of antimicrobial agents and anti-acid agents [12]. However, side effects for these regimes are common and a major concern is the development of antimicrobial resistance [13]. As a result, several naturally occurring substances have been investigated as potential alternatives for the treatment of $H$. pylori infection [14-18].

Almonds (Prunus dulcis D.A. Webb) are a rich source of nutrients and phytochemicals such as vitamin E, monounsatured fatty acids and polyunsatured fatty acids [19]. Other health promoting compounds mainly present in almond skins are polyphenols which have been shown to be bioaccessible during simulated digestion in the gut [20,21]. Among polyphenols, flavonoids are secondary metabolites well documented for their biological effects, including anticancer, antiviral, antimutagenic, anti-inflammatory and antimicrobial activities [22-24]. We have previously demonstrated that polyphenols from almond skins are active against Gram-positive bacteria including Staphylococcus aureus and Listeria monocytogenes and the Gram-negative Salmonella enterica [25]. Natural almond skins also induced a significant decrease in Herpes simplex virus type 2 replication [26]. The antioxidant and anti-inflammatory potential of almond skin polyphenols has also been demonstrated using an experimental model of inflammatory bowel disease [27].

The aim of the present study was to investigate the antimicrobial properties of natural almond skins before and after simulated human digestion in the upper GI tract and the pure flavonoid compounds epicatechin, naringenin and protocatechuic acid against $H$. pylori strains isolated from gastric biopsies of subjects attending an outpatient clinic in Southern Italy. Their clinical relevance has also been elucidated.

\section{Methods}

\section{Almond skins}

Natural almond skins (NS) were prepared from Californian almonds by treatment with liquid nitrogen as previously reported [20].

\section{In vitro digestion studies}

The protocol used to simulate digestion of natural almond skins under gastric and duodenal conditions in vitro has been previously described [21].

Briefly, for the gastric digestion, $1.5 \mathrm{~g}$ of NS was suspended in $12.4 \mathrm{~mL}$ acidic saline $(150 \mathrm{mM} \mathrm{NaCl}$,
$\mathrm{pH} 2.5$ ) and readjusted to $\mathrm{pH} 2.5$ with $\mathrm{HCl}$. Phosphatidylcholine (Lipid Products, UK) vesicle suspension, pepsin (Sigma, UK) and gastric lipase analogue (Amano Enzyme, Japan) were added so that the final concentrations were $2.4 \mathrm{mmol} / \mathrm{L}, 146 \mathrm{U} / \mathrm{mL}$ and $60 \mathrm{U} / \mathrm{mL}$, respectively. Gastric digestion was performed in a shaking incubator $\left(170 \mathrm{rpm}, 37^{\circ} \mathrm{C}\right)$ for $2 \mathrm{~h}$.

For the simulated gastric plus duodenal digestion, the $\mathrm{pH}$ was raised to 6.5 by addition of $\mathrm{NaOH}$ and the following enzymes were added: $\alpha$-chymotrypsin (Sigma, 5.9 U/mL), trypsin (Sigma, $104 \mathrm{U} / \mathrm{mL}$ ), colipase (Sigma, $3.2 \mu \mathrm{g} / \mathrm{mL}$ ), pancreatic lipase (Sigma, $54 \mathrm{U} / \mathrm{mL}$ ), and $\alpha$-amylase (Sigma, $25 \mathrm{U} / \mathrm{mL}$ ) in the presence of sodium taurocholate $(4 \mathrm{mmol} / \mathrm{L})$ and sodium glycodeoxycholate $(4 \mathrm{mmol} / \mathrm{L})$. Gastric plus duodenal digestion was performed in a shaking incubator $\left(170 \mathrm{rpm}, 37^{\circ} \mathrm{C}\right)$ for $1 \mathrm{~h}$.

\section{Almond skin extracts}

Polyphenol-rich extracts from NS, NS post in vitro gastric digestion (NS G) and NS post in vitro gastric plus duodenal digestion (NS G+D) were prepared as previously described and their composition has been previously reported [21].

\section{Patients, $\boldsymbol{H}$. pylori strains and culture conditions}

Two reference American Type Culture Collection strains of H. pylori (ATCC 43504 and ATCC 49503) and thirty two clinical isolates recovered from gastric biopsy samples of dyspeptic adults (23 women, 9 men; average age, 51 years) undergoing digestive endoscopy at the Endoscopy Unit of the Department of Internal Medicine of the University of Messina, Messina, Italy, were used in this study. None of the patients had previously undergone eradication therapy. All study subjects gave their informed consent and the study was approved by the local ethical committee (Comitato Etico Scientifico A.O.U. Policlinico "G. Martino" Messina, Italy). Diagnosis of peptic ulcer (PU) and non-ulcer dyspepsia (NUD) or gastritis was based on endoscopic examination of the stomach and duodenum. Biopsy samples were taken for each patient for culture. Isolates were derived from patients suffering from gastritis $(n=27 ; 84.37 \%)$, or NUD $(n=5 ; 15.62 \%)$.

Gastric biopsy specimens for culture were placed in the sterile screw-capped tubes containing $0.5 \mathrm{ml}$ sterile saline and transported to the microbiology laboratory within $2 \mathrm{~h}$. The samples were soaked and sowed in selective (Pylori agar, BioMérieux) and non-selective (Columbia agar with $7 \%$ horse blood, CB, Oxoid) culture media. Cultures were incubated for 7 days at $37^{\circ} \mathrm{C}$ under microaerophilic conditions. Grown bacteria were identified as $H$. pylori by typical morphology, Gram staining results and positive reactions to oxidase, catalase, and 
Table 1 Primers used for cytotoxin-associated gene (cagA) and vacuolating cytotoxin gene (vacA) typing of $H$. pylori

\begin{tabular}{|c|c|c|c|}
\hline Gene target & Primer designation & Nucleotide sequence & Amplicon size (bp) \\
\hline \multirow[t]{2}{*}{ vacAS-F } & VacAS-F & 5'-ATGGAAATACAACAAACACAC-3' & 259 (type s1) \\
\hline & VacAS-R & 5'-CTGCTTGAATGCGCCAAAC-3' & 286 (type s2) \\
\hline \multirow[t]{2}{*}{ vacA midregion } & VacAM-F & 5'-CAATCTGTCCAATCAAGCGAG-3' & 567 (type m1) \\
\hline & VacAM-R & 5'-GCGTCAAAATAATTCCAAGG-3' & 642 (type m2) \\
\hline \multirow[t]{2}{*}{$\operatorname{cag} A$} & CagA-F & 5'-GATAACAGGCAAGCTITTGAGAGGGA-3' & 393 \\
\hline & CagA-R & 5'-CCATGAATTITTGATCCGTTCGG-3' & \\
\hline
\end{tabular}

urease activities. The $\operatorname{cag} A$ and $v a c A$ status as a virulence factors have been determined in all strains by PCR method.

All strains were harvested by suspension in Brucella broth (Difco) supplemented with 10\% fetal bovine serum (BB, Euroclone) and 30\% glycerol and stored in liquid nitrogen until used.

\section{DNA extraction from $H$. pylori isolates}

DNA was extracted from $H$. pylori isolates using the QIAamp DNA Mini Kit (Qiagen, Milan, Italy) according to the manufacturer's instructions. Briefly, one colony was harvested from an agar plate and added to an appropriate volume of phosphate-buffered saline homogenized by vortexing. Twenty microliters of a proteinase $\mathrm{K}$ solution $(20 \mathrm{mg} / \mathrm{mL})$ and $200 \mu \mathrm{L}$ of buffer $\mathrm{AL}$ provided in the kit were then added, followed by incubation at $56^{\circ} \mathrm{C}$ for $10 \mathrm{~min}$. Next, $200 \mu \mathrm{L}$ of ethanol (96\%) were added. The mixture was then loaded onto the QIAamp spin column provided in the kit and centrifuged at $6000 \mathrm{~g}$ for $1 \mathrm{~min}$. The QIAamp spin column was placed in a $2-\mathrm{mL}$ collection microtube, and the tube containing the mixture was discarded. The column material was washed $(500 \mu \mathrm{L}$ each) with the first washing buffer (buffer AW1) and with the second washing buffer (buffer AW2) provided in the kit. Finally, the DNA was eluted with $150 \mu \mathrm{L}$ of a third buffer (buffer AE) provided in the kit.

\section{Oligonucleotide primers}

The primers targeting the vacA gene (region $\mathrm{m}$ and region s) and cagA genes [28] used in the PCR assay for the analysis of $H$. pylori isolates, are reported in Table 1. The primers were synthesised by MWG-Biotech AG (Mannheim, Germany).

\section{PCR conditions}

The amplification was performed using a PCR SprintThermal Cycler (Hybaid, Ashford, UK) and carried out in $50 \mu \mathrm{L}$ reaction volume containing $200 \mu \mathrm{mol} / \mathrm{L}$ (each) dNTP, $0.1 \mu \mathrm{mol} / \mathrm{L}$ (each) primer, 1X PCR buffer, $50 \mathrm{mmol} / \mathrm{L} \mathrm{KCl}, 10 \mathrm{mmol} / \mathrm{L}$ Tris- $\mathrm{HCl}$ pH 8.8, 0.1\% Triton $\mathrm{X}-100,50 \mathrm{mmol} / \mathrm{L} \mathrm{MgCl}_{2}, 2 \mathrm{U}$ of Taq DNA polymerase and $5 \mu \mathrm{L}$ of template DNA or water for the negative control. The temperature profile for the PCR was as follows: an initial step of $4 \mathrm{~min}$ at $95^{\circ} \mathrm{C}$, followed by a denaturation step for $1 \mathrm{~min}$ at $95^{\circ} \mathrm{C}$, an annealing step for $1 \mathrm{~min}$ at $52^{\circ} \mathrm{C}$ (for $v a c A$ PCR) or $59^{\circ} \mathrm{C}$ (for cagA PCR), and a primer extension step for $1 \mathrm{~min}$ at $72^{\circ} \mathrm{C}$. After the 35th cycle, the extension step was prolonged for $10 \mathrm{~min}$ in order to complete synthesis of all strands after which the samples were kept at $4^{\circ} \mathrm{C}$ until analysis. A negative control lacking of the DNA template was included in each experiment. The $H$. pylori strains used as positive controls in the PCR tests included $H$. pylori ATCC 43504 and H. pylori ATCC 49503. Detection of PCR products was performed by gel electrophoresis. Samples $(5 \mu \mathrm{L})$ of final PCR products were loaded onto $1.5 \%$ agarose gel and subjected to electrophoresis in $1 \mathrm{X}$ TAE $(0.04 \mathrm{~mol} / \mathrm{L}$ Tris-acetate, $0.001 \mathrm{~mol} / \mathrm{L}$ EDTA) buffer for $60-90 \mathrm{~min}$ at $100 \mathrm{~V}$. The gels were stained with ethidium bromide and photographed under UV light trans-illumination. A 100-bp DNA ladder (BioLab New England, Celbio, Milan, Italy) was included on each gel as a molecular size standard.

\section{Susceptibility testing}

The minimum inhibitory concentration (MIC) was assayed by the standard agar dilution method according to the guidelines of the Clinical and Laboratory Standards Institute (CLSI) [29] using CB. Twofold serial dilutions of the compound tested ranging from $0.016 \mu \mathrm{g} / \mathrm{mL}$ to $1.024 \mu \mathrm{g} / \mathrm{mL}$ were used. Frozen stock cultures were

Table 2 Prevalence of cagA and allelic variants of vacA on the $H$. pylori strains

\begin{tabular}{ccccccc}
\hline Gastroduodenal condition & \multicolumn{2}{c}{ CagA } & \multicolumn{2}{c}{ VacA } \\
\hline & CagA & CagA & s1 & s2 & m1 & m2 \\
Gastritis $^{*}$ & $15(55.5 \%)$ & $12(44.5 \%)$ & $\mathbf{2 1}(77.8 \%)$ & $\mathbf{6 ( 2 2 . 2 \% )}$ & $\mathbf{1 7}(63 \%)$ & $\mathbf{1 0}(37 \%)$ \\
NUD $^{* *}$ & $\mathbf{0}(0 \%)$ & $\mathbf{5 ( 1 0 0 \% )}$ & $\mathbf{3}(60 \%)$ & $\mathbf{2 ( 4 0 \% )}$ & $\mathbf{2 ( 4 0 \% )}$ & $\mathbf{3}(60 \%)$ \\
\hline
\end{tabular}

*Strains isolated from patients with gastritis $(n=27){ }^{* *}$ Strains isolated from patients with non-ulcer dyspepsia $(n=5)$. 
Table 3 Prevalence of cagA related to the main allelic combinations of vacA

\begin{tabular}{ccccccc}
\hline Gastroduodenal condition & \multicolumn{3}{c}{ CagA+ } & \multicolumn{2}{c}{ CagA- } \\
\hline Gastritis $^{*}$ & $\mathbf{s 1 m 1}$ & $\mathbf{s 1 m 2}$ & $\mathbf{s 2 m 2}$ & $\mathbf{s 1 m 1}$ & $\mathbf{s 1 m 2}$ & $\mathbf{s 2 m 1 ~ s 2 m 2 ~}$ \\
NUD $^{* *}$ & $\mathbf{8}(53.3 \%)$ & $\mathbf{5}(33.3 \%)$ & $\mathbf{2}(13.4 \%)$ & $\mathbf{6 ( 5 0 \% )}$ & $\mathbf{2}(16.7 \%)$ & $\mathbf{3}(25 \%) \mathbf{1}(8.3 \%)$ \\
& $\mathbf{0}(0 \%)$ & $\mathbf{0}(0 \%)$ & $\mathbf{0}(0 \%)$ & $\mathbf{1}(20 \%)$ & $\mathbf{2}(40 \%)$ & $\mathbf{1}(20 \%) \mathbf{1}(20 \%)$ \\
\hline
\end{tabular}

*Strains isolated from patients with gastritis $(n=27)^{* *}$ Strains isolated from patients with non-ulcer dyspepsia $(n=5)$.

thawed and subcultured on $\mathrm{CB}$ and grown for 3 days under microaerophilic conditions. Bacterial growth was taken from the plates, resuspended in $\mathrm{BB}$ and grown under shaking $(125 \mathrm{rpm})$ at $37^{\circ} \mathrm{C}$ for 24 h. H. pylori cultures in the exponential phase of growth were diluted with $\mathrm{BB}$ to contain about $5 \times 10^{7} \mathrm{CFU} / \mathrm{mL}$ by adjusting the turbidity of the suspension to match the MacFarland no. 1 standard. Ten-microliter aliquots of the suspension were inoculated on $\mathrm{CB}$ containing twofold serial dilutions of the compound tested. Compound-free CB media were included in each experiment to confirm the viability of the inoculum and to observe the growth of any contaminants. CB incorporating twofold serial dilutions of the solvent dimethil sulfoxide was included as a growth control to ensure that the viability of the $H$. pylori strains was not affected by the dimethil sulfoxide used to dissolve the compound. All plates were incubated at $37^{\circ} \mathrm{C}$ in a microaerophilic atmosphere and examined after 3 days. For quality control, H. pylori ATCC strains 43504 and 49503 were tested in each run. Amoxicillin (Sigma Aldrich S.r.l., Italy), and clarithromycin (Abbott S. p.A., Italy), were used as control compounds for comparative analyses. According to CLSI breakpoints, the resistance breakpoints were $0.5 \mu \mathrm{g} / \mathrm{mL}$ for amoxicillin and $1 \mu \mathrm{g} / \mathrm{mL}$ for clarithromycin [29]. The MIC was considered the lowest concentration at which the compound inhibited the development of visible bacterial growth on the agar plates. All MIC determinations were performed in duplicate for each strain.

\section{Results}

To type the H. pylori strains isolated from the patients examined in this study, we amplified by PCR different alleles of the genes of the two major virulence factors of

Table 4 Minimum inhibitory concentration of almond skin extracts against $\boldsymbol{H}$. pylori (ATCC strains and clinical isolates)

\begin{tabular}{cccc}
\hline & MIC range & MIC $_{\mathbf{5 0}}$ & MIC $_{\mathbf{9 0}}$ \\
\hline NS & $64-128$ & 64 & 128 \\
NS G & $128-512$ & 128 & 256 \\
NS G + D & $256-512$ & 256 & 512 \\
\hline
\end{tabular}

Values are expressed as $\mu \mathrm{g} \mathrm{ml}^{-1}$.

NS: Natural almond skin polyphenol-rich extract.

NS G: Natural almond skin polyphenol-rich extract post gastric digestion. NS G + D: Natural almond skin polyphenol-rich extract post gastric plus duodenal digestion. this bacteria, cagA and $v a c A$. The amplification results are shown in Table 2. Fifteen out of $32 \mathrm{H}$. pylori isolates were $\operatorname{cag} A$ positive, representing $55.5 \%(15 / 27)$ of the isolates recovered from patients with gastritis. No strain identified from patients with NUD was cagA positive. The prevalence of the allelic variants of $\mathrm{s} 1$ and $\mathrm{m} 1$ of $v a c A$ was higher in the strains isolated from patients with gastritis compared with the strains isolated from NUD patients $(77.8 \%$ versus $60 \%$, and $63 \%$ vs $40 \%$, respectively). When the $\operatorname{cag} A$ and $v a c A$ genotypes were combined and analyzed in relation to the clinical outcome (Table 3), the $\operatorname{cag} A+$ strains with the allelic variant $\mathrm{s} 1 \mathrm{~m} 1$ of $v a c A$ were only present in the strains isolated from gastritis patients (53.3\%).

The MIC values of natural almond skin (NS), NS post in vitro gastric digestion (NS G) and NS post in vitro gastric plus duodenal digestion (NS G+D) against 34 H. pylori strains including 2 ATCC $H$. pylori strains are shown in Table 4. Results of negative controls containing DMSO (maximum 1\% v/v) indicated the complete absence of inhibition of all the H. pylori strains tested (data not shown). All extracts inhibited the growth of both the clinical isolates and the reference strains. As expected, NS was the most effective (MIC range, 64 to $128 \mu \mathrm{g} / \mathrm{mL}$ ), followed by NS G (MIC range, 128 to $512 \mu \mathrm{g} / \mathrm{mL}$ ) and NS $\mathrm{G}+\mathrm{D}$ (MIC range, 256 to $512 \mu \mathrm{g} / \mathrm{mL}$ ). MIC values of 64 , 128 and $256 \mu \mathrm{g} / \mathrm{mL}$ NS, NS G and NS G + D, respectively, inhibited the growth of $50 \%$ of the H. pylori tested strains. These results clearly confirm that all three polyphenolrich extracts acted as good growth inhibitors against $H$. pylori with different virulence irrespective of the cagA and $v a c A$ status. In other words, there was no difference in the suppression of growth between the $8 \mathrm{H}$. pylori clinical isolates harboring the $\operatorname{cag} A^{+} / \mathrm{vacAs} 1 / \mathrm{m} 1$ genotype, including the quality control strains (ATCC 43504 and 49503), and the other H. pylori genotypes.

Table 5 Minimum inhibitory concentration of almond skin flavonoids against H.pylori (ATCC strains and clinical isolates)

\begin{tabular}{cccc}
\hline & MIC range & MIC $_{\mathbf{5 0}}$ & MIC $_{\mathbf{9 0}}$ \\
\hline Epicatechin & $128-1024$ & 512 & 1024 \\
Naringenin & $128-1024$ & 256 & 512 \\
Protocatechuic acid & $128-512$ & 128 & 256 \\
\hline
\end{tabular}

Values are expressed as $\mu \mathrm{g} \mathrm{ml}^{-1}$. 
The MIC results of epicathechin, naringerin and protocatechuic acid against $H$. pylori strains are reported in Table 5. Protocatechuic acid showed the greatest activity with MIC values of $128 \mu \mathrm{g} / \mathrm{mL}$ and $256 \mu \mathrm{g} / \mathrm{mL}$ against $50 \%$ and $90 \%$ of the tested strains, respectively. Epicatechin was the least effective compound against $H$. pylori (MIC of $512 \mu \mathrm{g} / \mathrm{mL}$ against $50 \%$ of the H. pylori strains).

All $H$. pylori strains tested were susceptible to amoxicillin $\left(\mathrm{MIC}_{90} 0.25 \mu \mathrm{g} / \mathrm{mL}\right.$; range between $\left.0.016-0.25 \mu \mathrm{g} / \mathrm{mL}\right)$. The $\mathrm{MIC}_{90}$ value of clarithromycin against $H$. pylori isolates was $0.5 \mu \mathrm{g} / \mathrm{mL}$ with MIC values ranging between 0.016 and $4 \mu \mathrm{g} / \mathrm{mL}$. Two (6\%) out of 32 isolates tested were clarithromycin resistant, one of which was isolated from patients suffering from gastritis harbouring the $\operatorname{cag} A^{+} / \mathrm{vac} A \mathrm{~s} 1 / \mathrm{m} 1$ genotype.

The two clarithromycin-resistant strains were inhibited by almond skin extracts (NS, NS G, NS G + D) at $128 \mu \mathrm{g} / \mathrm{mL}$; the MIC values of pure compounds (epicatechin, naringenin, protocatechuic acid) against these two strains were 256,256 , and $128 \mu \mathrm{g} / \mathrm{mL}$, respectively.

Quality control MICs were within acceptable limits for all antimicrobial susceptibility testing.

\section{Discussion}

The results reported in the present paper demonstrated that polyphenols present in almond skins are effective against $H$. pylori strains, both ATCC and clinical isolates. As previously reported [21,26], NS was the most active against the tested strains. This result could be due to the highest polyphenols concentration in NS, whereas a decrease in the total phenolic content was observed post in vitro gastric and post in vitro gastric plus duodenal digestion [21]. Catechin, epicatechin, kaempferol (aglycone and conjugated) and isorhamnetin (aglycone and conjugated) were the major compounds identified in NS [21], leading to assume the combination of these polyphenols was responsible for the higher activity against H. pylori. Quercetin and kaempferol were shown to be active against a $\operatorname{CagA}+$ and a $\operatorname{CagA}$ - strain of $H$. pylori and a relationship between antimicrobial potential and antioxidant activity was only reported for the CagA- G 21 strain [18]. The same authors have also recently reported an increased susceptibility to resveratrol of $H$. pylori strains isolated from patients suffering from gastric carcinomas [30]. The investigation of the isolated compounds in the present work demonstrated that protocatechuic acid was more active than naringenin and epicatechin and the effectiveness of protocathechic acid against $H$. pylori in broth and stomach homogenates from mice has also been demonstrated by Liu et al. [31], with no differences between antibiotic susceptible and resistant strains. Other investigations have reported promising effect of natural compounds, such as hydrolysable tannins and lignans, on the proliferation of H. pylori and the prevention of gastric carcinogenesis [32,33]. Reports on the mechanism of action of a range of flavonoids have shown that isoflavones and chalcones inhibited the urease secreted by $H$. pylori to survive the acidic conditions found in the stomach $[34,35]$. Other flavonoids may also be responsible for the neutralization of the vacA via interference of the toll-like receptor 4 signaling induced by $H$. pylori [36,37]. A recent study reported that the antimicrobial potential of the oligopeptide $\mathrm{C}_{12} \mathrm{~K}-2$ against $H$. pylori has a dual mode of action on both membrane and cytoplasmatic components [38]. Although the rate of resistance to clarithromycin has significantly increased in several countries (13), the observed resistance to this antibiotic in the H. pylori isolates tested in the present work was surprisingly low (6\%).

\section{Conclusions}

In conclusion, we have shown that polyphenols from almond skins were effective in vitro against $H$. pylori, irrespective of the bacterial genotype which is independent of the presence of the cagA, and could therefore be used in combination with antibiotics as a novel strategy for antibiotic resistance.

\section{Competing interests}

The authors have received a research grant from the Almond Board of California.

\section{Authors' contribution}

CB, MTF, GM conceived the study and participated in its design. EL, AF, SZ carried out the experiments and performed the data analyses. EL and SZ participated in the isolation of clinical strains. EL carried out the PCR amplification. GM coordinated, supervised the study and critically revised the manuscript. CB, AF, EL, SZ, MTF, GM drafted the manuscript. All authors have read and approved the final manuscript.

\section{Acknowledgements}

We thank Dr Karen Lapsley from the Almond Board California for supplying the almonds.

This study was supported by the Almond Board of California and the University of Messina, Italy.

\section{Author details}

${ }^{1}$ Dipartimento di Scienze del Farmaco e Prodotti per la Salute, University of Messina, Viale Annunziata, Messina 98100, Italy. ${ }^{2}$ Dipartimento di Scienze Pediatriche, Ginecologiche, Microbiologiche e Biomediche, University of Messina, Policlinico Universitario, Viale Gazzi, Messina 98125, Italy. ${ }^{3}$ The Model Gut, Institute of Food Research, Norwich Research Park, Colney Lane, Norwich NR4 7UA, UK.

Received: 20 January 2013 Accepted: 26 April 2013

Published: 9 May 2013

\section{References}

1. Ferreira AC, Isomoto H, Moriyama M, Fujioka T, Machado JC, Yamaoka Y: Helicobacter and gastric malignancies. Helicobacter 2008, 13:28-34.

2. Kandulski A, Selgrad M, Malfertheiner P: Helicobacter pylori infection: a clinical overview. Dig Liver Dis 2008, 40:619-626.

3. Minami M, Ando T, Hashikawa SN, Torii K, Hasegawa T, Israel DA, Ina K, Kusugami K, Goto H, Ohta M: Effect of glycine on Helicobacter pylori in vitro. Antimicrob Agents Chemother 2004, 48:3782-3788.

4. Covacci A, Telford JL, Del Giudice G, Parsonnet J, Rappuoli R: Helicobacter pylori virulence and genetic geography. Science 1999, 284:1328-1333. 
5. Atherton JC, Cao P, Peek RM Jr, Tummuru MK, Blaser MJ, Cover TL: Mosaicism in vacuolating cytotoxin alleles of Helicobacter pylori. Association of specific vacA types with cytotoxin production and peptic ulceration. J Biol Chem 1995, 270:17771-17777.

6. van Doorn LJ, Figueiredo C, Sanna R, Plaisier A, Schneeberger P, de Boer W Quint W: Clinical relevance of the cagA, vacA, and iceA status of Helicobacter pylori. Gastroenterology 1998, 115:58-66.

7. Covacci A, Censini S, Bugnoli M, Petracca R, Burroni D, Macchia G, Massone A, Papini E, Xiang Z, Figura N, Rappuoli R: Molecular characterization of the 128-kDa immunodominant antigen of Helicobacter pylori associated with cytotoxicity and duodenal ulcer. Proc Natl Acad Sci USA 1993, 90:5791-5795

8. Akopyants NS, Clifton SW, Kersulyte D, Crabtree JE, Youree BE, Reece CA, Bukanov NO, Drazek ES, Roe BA, Berg DE: Analyses of the cag pathogenicity island of Helicobacter pylori. Mol Microbiol 1998, 28:37-53.

9. Peek RM Jr, Blaser MJ, Mays DJ, Forsyth MH, Cover TL, Song SY, Krishna U, Pietenpol JA: Helicobacter pylori strain-specific genotypes and modulation of the gastric epithelial cell cycle. Cancer Res 1999, 59:6124-6131.

10. Bagnoli F, Buti L, Tompkins L, Covacci A, Amieva MR: Helicobacter pylori CagA induces a transition from polarized top invasive phenotypes in MDCK cells. Proc Natl Acad Sci USA 2005, 102:16339-16344.

11. Kusters JG, van Vliet AH, Kuipers EJ: Pathogenesis of Helicobacter pylori infection. Clin Microbiol Rev 2006, 19:449-490.

12. Graham DY: Therapy of Helicobacter pylori: current status and issues. Gastroenterology 2000, 118(Suppl 1):S2-S8.

13. Gerrits MM, van Vliet AH, Kuipers EJ, Kusters JG: Helicobacter pylori and antimicrobial resistance: molecular mechanisms and clinical implications. Lancet Infect Dis 2006, 6:699-709.

14. Bae EA, Han MJ, Kim DH: In vitro anti-Helicobacter pylori activity of some flavonoids and their metabolites. Planta Med 1999, 65:442-443.

15. Fukai T, Marumo A, Kaitou K, Kanda T, Tereda S, Nomura T: Anti-Helicobacter pylori flavonoids from licorice extract. Life Sci 2002, 71:1449-1463.

16. Nostro A, Cellini L, Di Bartolomeo S, Di Campli E, Grande R, Cannatelli MA, Marzio L, Alonzo V: Antibacterial effect of plants extracts against Helicobacter pylori. Phytother Res 2005, 19:198-202

17. Shin JE, Kim JM, Bae EA, Hyun YJ, Kim DH: In vitro inhibitory effect of flavonoids on growth, infection and vacuolation of Helicobacter pylori. Planta Med 2005, 71:197-201.

18. Martini S, D'Addario C, Colacevich A, Focardi S, Borghini F, Santucci A, Figura N, Rossi C: Antimicrobial activity against Helicobacter pylori strains and antioxidant properties of blackberry leaves (Rubus ulmifolius) and isolated compounds. Int J Antimicrob Agents 2009, 34:50-59.

19. Mandalari G, Faulks RM, Rich GT, Lo Turco V, Picout DR, Lo Curto RB, Bisignano G, Dugo P, Dugo G, Waldron KW, Ellis PR, Wickham MS: Release of protein, lipid, and vitamin $E$ from almond seeds during digestion. J Agric Food Chem 2008, 56:3409-3416.

20. Mandalari G, Tomaino A, Arcoraci T, Martorana M, Lo Turco V, Cacciola F, Rich GT, Bisignano C, Saija A, Dugo P, Cross KL, Parker ML, Waldron KW, Wickham MS J: Characterization of polyphenols, lipids and dietary fibre from almond skins (Amygdalus communis L.). J Food Comp Anal 2010, 23:166-174.

21. Mandalari G, Tomaino A, Rich GT, Lo Curto R, Arcoraci T, Martorana M, Bisignano C, Saija A, Parker ML, Waldron KW, Wickham MSJ: Polyphenol and nutrient release from skin of almonds during simulated human digestion. Food Chem 2010, 122:1083-1088.

22. Vuorela S, Kreander K, Karonen M, Nieminen R, Hämäläinen M, Galkin A, Laitinen L, Salminen JP, Moilanen E, Pihlaja K, Vuorela H, Vuorela P, Heinonen M: Preclinical evaluation of rapeseed, raspberry, and pine bark phenolics for health related effects. J Agric Food Chem 2005, 53:5922-5931.

23. Marino A, Bellinghieri V, Nostro A, Miceli N, Taviano MF, Guvenc A Bisignano $G$ : In vitro effect of branch extracts of Juniperus species from Turkey on Staphylococcus aureus biofilm. FEMS Immunol Med Microbiol 2010, 59:470-476.

24. Miceli N, Trovato A, Marino A, Bellinghieri V, Melchini A, Dugo P, Cacciola F, Donato P, Mondello L, Guvenc A, De Pasquale R, Taviano MF: Phenolic composition and biological activities of Juniperus drupacea Labill. Berries from Turkey. Food Chem Toxicol 2011, 49:2600-2608.

25. Mandalari G, Bisignano C, D’Arrigo M, Ginestra G, Arena A, Tomaino A, Wickham MS: Antimicrobial potential of polyphenols extracted from almond skins. Lett Appl Microbiol 2010, 51:83-89.
26. Arena A, Bisignano C, Stassi G, Mandalari G, Wickham MSJ, Bisignano G: Immunomodulatory and antiviral activity of almond skins. Immunol Lett 2010, 132:18-23.

27. Mandalari G, Bisignano C, Genovese T, Mazzon E, Wickham MS, Paterniti I, Cuzzocrea S: Natural almond skin reduced oxidative stress and inflammation in an experimental model of inflammatory bowel disease. Int Immunopharmacol 2011, 11:915-924.

28. Faundez G, Troncoso M, Figueroa G: cagA and vacA in strains of Helicobacter pylori from ulcer and non-ulcerative dyspepsia patients. BMC Gastroenterol 2002, 2:20

29. Clinical and Laboratory Standards Institute: Performance standards for antimicrobial susceptibility testing; twentieth informational supplement. M100-S22. Wayne: PA: CLSI; 2012.

30. Martini S, Bonechi C, Rossi C, Figura N: Increased susceptibility to resveratrol of Helicobacter pylori strains isolated from patients with gastric carcinoma. J Nat Prod 2011, 74:2257-2260.

31. Liu W, Hsu C, Yin M: In vitro anti-Helicobacter pylori activity of diallyl sulphides and protocathecuic acid. Phytother Res 2008, 22:53-57.

32. Funatogawa $K$, Hayashi S, Shimomura H, Yoshida T, Hatano T, Ito H, Hirai $Y$ : Antibacterial activity of hydrolysable tannins derived from medicinal plants against Helicobacter pylori. Microbiol Immunol 2004, 48:251-261.

33. Toyoda T, Tsukamoto T, Mizoshita T, Nishibe S, Deyama T, Takenata Y, Hirano N, Tanaka H, Takasu S, Ban H, Kumagai T, Inada K, Utsunomiya H, Tatematsu M: Inhibitory effect of nordihydroguaiaretic acid, a plant lignan, on Helicobacter pylori-associated gastric carcinogenesis in Mongolian gerbils. CancSci 2007, 98:1689-1695.

34. Xiao Z-P, Shi D-H, Li H-Q, Zhang L-N, Xu C, Zhu H-L: Polyphenols based on isoflavones as inhibitors of Helicobacter pylori urease. Bioorg Med Chem 2007, 15:3703-3710.

35. Ansari FL, Umbreen S, Hussain L, Makhmoor T, Nawaz SA, Lodhi MA, Khan SN, Shaheen F, Choudhary MI, Atta-ur-Rahman: Syntheses and biological activities of chalcones and 1,5-benzothiazepine derivatives: promising new free-radical scavengers, and esterases, ureases and a-glucosidase inhibitors. Chem Biodivers 2005, 2:487-496.

36. Tombola F, Campello S, De Luca L, Ruggiero P, Del Giudice G, Papini E, Zoratti M: Plant polyphenols inhibit VacA, a toxin secreted by the gastric pathogen Helicobacter pylori. FEBS Lett 2003, 543:184-189.

37. Lee KM, Yeo M, Choue JS, Jin JH, Park SJ, Cheong JY, Lee KJ, Kim JH, Hahm KB: Protective mechanism of epigallocatechin-3-gallate against Helicobacter pylori-induced gastric epithelial cytotoxicity via the blockage of TLR-4 signalling. Helicobacter 2004, 9:632-642.

38. Makobongo MO, Gancz H, Carpenter BM, McDaniel DP, Merrel DS: The oligo-acyl lysyl antimicrobial peptide $\mathrm{C}_{12} \mathrm{~K}-2$ exhibits a dual mechanism of action and demonstrated strong in vivo efficacy against Helicobacter pylori. Antimicrob Ag Chemother 2012, 56:378-390.

doi:10.1186/1471-2180-13-103

Cite this article as: Bisignano et al:: Antibacterial activities of almond skins on cagA-positive and-negative clinical isolates of Helicobacter pylori. BMC Microbiology 2013 13:103.

\section{Submit your next manuscript to BioMed Central and take full advantage of:}

- Convenient online submission

- Thorough peer review

- No space constraints or color figure charges

- Immediate publication on acceptance

- Inclusion in PubMed, CAS, Scopus and Google Scholar

- Research which is freely available for redistribution 